\title{
BMJ Open Birth characteristics in a clinical sample of women seeking infertility treatment: a case-control study
}

\author{
Josefin Vikström, Mats Hammar, Ann Josefsson, Marie Bladh, Gunilla Sydsjö
}

To cite: Vikström J, Hammar M, Josefsson A, et al. Birth characteristics in a clinical sample of women seeking infertility treatment: a case-control study. BMJ Open 2014;4:e004197. doi:10.1136/bmjopen-2013004197

- Prepublication history for this paper is available online. To view these files please visit the journal online (http://dx.doi.org/10.1136/ bmjopen-2013-004197).

Received 8 October 2013 Revised 10 December 2013 Accepted 17 January 2014

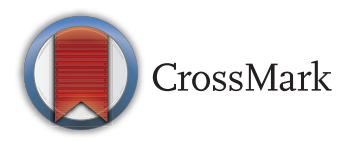

Division of Obstetrics and Gynecology, Department of Clinical and Experimental Medicine, Faculty of Health Sciences, Department of Obstetrics and Gynecology in Linköping, Linköping University, County Council of Östergötland, Linköping, Sweden

Correspondence to Josefin Vikström; josefin.vikstrom@lio.se

\section{ABSTRACT}

Objective: To determine the distribution of low birth weight (LBW), preterm birth, small for gestational age (SGA) and large for gestational age (LGA) by main cause of infertility (female, combined, male, unexplained) in women seeking infertility treatment.

Design: A case-control study.

Setting: A Centre for Reproductive Medicine in Sweden.

Participants: All women $(n=1293)$ born in Sweden in 1973 or later and who were part of heterosexual couples seeking infertility treatment at a Centre of Reproductive Medicine from 2005 to 2010 were asked to participate. Those who had not begun the diagnostic process and who declined participation in the study were excluded. In total, 1206 women (94.5\%) participated in the study.

Main outcome measures: Main cause of infertility (female, combined, male, unexplained) collected from the patients' medical charts. LBW $(<2500 \mathrm{~g})$, preterm birth (<37 weeks), SGA (<-2SD of the mean weight for the gestational length) and LGA $(>+2 S D$ of the mean weight for the gestational length), collected from the Swedish Medical Birth Register.

Results: The risk of being born with LBW was increased about 2.4 times $(\mathrm{OR}=2.40, \mathrm{Cl} 1.13$ to 5.07 , $\mathrm{p}=0.02$ ) in women seeking treatment for infertility due to female causes rather than for male or unexplained causes. Women with a female infertility factor were 2.7 times more likely to be born SGA (OR=2.73, $\mathrm{Cl} 1.02$ to $7.34, p=0.047$ ) compared with those in whom the cause of infertility was unexplained.

Conclusions: Women born with LBW or SGA seem to suffer an increased risk of infertility due to a female factor. Thus, infants born with birth characteristics that deviate from the norm may be at greater risk of difficulties in childbearing later on in life. Since this study is the first of its kind, more studies are needed to verify the associations found in this study and to determine their nature.

\section{INTRODUCTION}

Only a few decades ago, mortality was high in infants born very prematurely and/or with very low birth weight (VLBW). Nowadays, owing to advances in medical research and

\section{Strengths and limitations of this study}

- No previous studies have examined the possible association between birth characteristics and infertility later on in life.

- The results suggest that women born with low birth weight and/or small for gestational age are at increased risk of infertility later on in life.

- This study is based on data from the national Medical Birth Register, which is a reliable source of data decreasing dependence on unsecure patient data.

- Women diagnosed with infertility were compared with those who had a spouse with a male infertility factor or the women where the cause of infertility was unexplained since a well-matched control group would be difficult to form.

care, survival is the expected outcome for these individuals. However, there may be health implications of being born prematurely or with LBW. Studies have shown an association between restricted fetal growth and diseases later in life, for example those inherent to the metabolic syndrome. ${ }^{1-4}$ One theory giving a plausible explanation of this connection is Barker's 'the foetal origins of adult disease hypothesis'. ${ }^{5}$ This hypothesis states that when the fetus is exposed to an unfavourable environment, the development of body systems will be affected, resulting in a change in their function. These changes become risk factors for disease later in life. ${ }^{25}$ Previous studies have shown some variations from the norm regarding the function and structure of the reproductive organs as well as the reproductive patterns among individuals born with VLBW ( meaning $<1500 \mathrm{~g}$ ), or small for gestational age (SGA; meaning a birth weight $<-2 \mathrm{SD}$ of the mean weight for the gestational length) ${ }^{6-8}$ One Swedish study showed that women born with VLBW were less likely, whereas women born SGA were more likely, to give birth during their early reproductive years compared with controls. ${ }^{9-12}$ Studies have indicated that there 
may be abnormalities in hormonal levels and testes size in adult men born growth restricted while, in women, reduced ovulation rate and smaller internal genitalia were found. ${ }^{13-15}$

There are thus studies indicating that there may be abnormalities in the function and structure of the reproductive organs as well as reproductive patterns in individuals born small, growth restricted and/or prematurely. However, there are no previous studies on the possible association between birth characteristics and infertility among these individuals.

The aim of the present study was to examine the distribution of LBW, SGA, LGA (large for gestational age) and premature birth in a population of Swedish women, each being part of a couple seeking treatment for infertility due to female causes rather than male or unexplained causes.

We hypothesised that the functions of the reproductive system are affected by growth restriction and/or premature birth, as stated by Barker's hypothesis, which will manifest itself as an increased number of individuals born prematurely, SGA or with LBW in women seeking treatment for infertility due to female causes rather than male or unexplained causes.

\section{METHODS}

\section{Population}

This was a retrospective case-control register study, which included all women born in Sweden in 1973 or later who were part of a heterosexual couple accepted for infertility treatment at the Centre for Reproductive Medicine (RMC), Linköping University Hospital, Sweden, from 1 January 2005 to 31 December 2010. This time period was selected to include a maximum number of women seeking infertility treatment who were included in the national Medical Birth Register (MBR), which was created in 1973. Those who had neither filled out the introductory health questionnaire nor had laboratory tests taken, and thus had not undergone a complete diagnostic process, were not included. The remaining 1293 women received a letter asking for the women's permission to access information from their medical charts and the MBR. Permission was received from $94.5 \% \quad(n=1222)$ of the women. Throughout this article, the woman is the unit of analysis, and in all instances that birth characteristics are described, it is the woman's own birth characteristics that are referred to and in no case her offspring.

\section{Infertility treatment at RMC, Linköping University hospital}

Couples who are infertile and who are living in the southeast healthcare region of Sweden, which has a population of 1.7 million inhabitants, can receive a referral to RMC, Linköping University hospital for infertility treatment. In order to be accepted for the treatment paid by the County Council of Östergötland, responsible for healthcare in the region, a number of criteria stated in the department's guidelines must be fulfilled, including an upper body mass index (BMI) limit of $30 \mathrm{~kg} / \mathrm{m}^{2}$ for the woman. Also, the couple must be married or cohabiting for at least 2 years before they are accepted for treatment.

Couples accepted for infertility treatment are routinely asked to fill out a questionnaire which contains questions regarding age, height and weight, chronic illnesses, smoking (1, yes; 2 , no), the use of snuff ( 1 , yes; 2 , no), regular intake of medication and allergies. Also, information about the number of previous pregnancies, children, abortions and miscarriages is requested. This information is added to the patients' medical charts. After that, an individually adapted investigation of the cause of infertility is performed. This investigation includes sperm samples, gynaecological examination and an ultrasound including diagnosis of patent fallopian tubes, laboratory tests etc. Information about the type of infertility treatment chosen is noted in the patient's medical charts.

\section{Information gathered from medical charts}

For the present study, information was collected from the medical charts of the participants about the information given in the introductory questionnaire and also about infertility type (1, female; 2, male; 3 , combined; 4, unexplained), which had been determined by the physician conducting the infertility investigation. The information was retrieved from the patients' charts by two midwives trained in assisted reproduction and by the corresponding author. Patients were asked to state any chronic illnesses in an open-ended question which, for this study, was grouped into relevant categories by the corresponding author. BMI was calculated from the height and weight and divided into four categories $\left(1,<18.5 \mathrm{~kg} / \mathrm{m}^{2} ; 2, \quad 18.5-24.99 \mathrm{~kg} / \mathrm{m}^{2} ; 3, \quad 25.00-29.99\right.$ $\left.\mathrm{kg} / \mathrm{m}^{2} ; 4, \geq 30.00 \mathrm{~kg} / \mathrm{m}^{2}\right){ }^{16}$

\section{The national Medical Birth Register}

Information regarding the birth characteristics of the women was collected from the national MBR, which includes information on $97-99 \%$ of pregnancies that have resulted in deliveries in Sweden since 1973. The register contains information about the pregnancy, delivery and antenatal health of the child and is based on the medical charts from maternal healthcare, obstetric care and infant care. ${ }^{8}$ The MBR is thoroughly described by Harlow et al. ${ }^{17}$ The information collected about the birth characteristics of the woman included the height, weight and birth week. Those weighing $\leq 2500 \mathrm{~g}$ were classified as being of LBW, those weighing $\leq 1500$ were classified as being VLBW and those whose birth weight was smaller than -2SD of the mean weight for the gestational length were classified as being SGA, while those larger than +2SD of the mean weight for the gestational length were classified as LGA. ${ }^{17} 18$ Moderate preterm birth was defined as being born before gestational week 
37 while very preterm birth was defined as being born before the 32nd week. ${ }^{6}$

\section{Statistics}

Statistical analyses were performed using IBM SPSS V.20 (IBM Inc, Armonk, New York, USA). All analyses were two-sided and the significance level was set at $\mathrm{p} \leq 0.05$. The distributions of year of birth, BMI, highest level of education, LBW, VLBW, LGA, SGA, moderate preterm birth and very preterm birth divided by the number of individuals in the categories female, male, combined and unexplained infertility were calculated. The female and combined categories were added together to form a separate category in order to include all women diagnosed with infertility in the same category. The distribution of the above-mentioned variables was also calculated for this category. For all variables, numbers and percentages were given.

Multinominal regression analyses were performed to determine any differences between the three categories of women; those where the main cause of infertility was female/combined, male or unexplained in regard to preterm birth ( $<37$ weeks), LBW $(<2500 \mathrm{~g})$, SGA or LGA. A second set of analyses was performed which included BMI and parity as factors in order to minimise the risk of bias. Bivariate logistic regression was used to determine any differences between the two categories of women: those where the main cause of infertility was female/combined with those where the cause was male/ unexplained infertility in regard to preterm birth $(<37$ weeks), LBW $(<2500 \mathrm{~g})$, SGA or LGA. These analyses were also repeated while controlling for BMI and parity. For the regression analyses, VLBW and very preterm birth were not included due to the too small number of positive outcomes in these categories.

\section{RESULTS}

A total of 1293 women met the inclusion criteria and thus received a letter of permission. In total, 1222 women $(94.5 \%)$ agreed to participate in the study. As infertility type was not specified in their medical charts, 16 women were excluded from the analyses. Thus, the population used for statistical analyses consisted of 1206 women $(93.3 \%)$. Since there was some information lacking in the medical charts, the numbers of participants do not add up to 1206 for all variables. The women were born in 1973-1987 with a median birth year of 1976 (table 1). The infertility was due to female causes in $38.5 \% \quad(n=464)$ of the cases, male causes in $26.8 \%(\mathrm{n}=323)$ of the cases, combined causes in $6.6 \%$ $(n=79)$ of the cases and in $28.2 \%(n=340)$ of the cases was unexplained. Approximately $69 \%(\mathrm{n}=796)$ of the women had a normal BMI (18.5-24.99), while 23.2\% $(\mathrm{n}=268)$ were overweight $(25-29.99), 5.2 \%(\mathrm{n}=60)$ obese $(\geq 30)$ and $2.4 \%(n=27)$ underweight $(<18.5$; table 1$)$. The corresponding numbers for the category containing the women where the infertility was female or combined were $66 \%(\mathrm{n}=343), 23.7 \% \quad(\mathrm{n}=123), 7.9 \% \quad(\mathrm{n}=41)$ and $2.5 \%(\mathrm{n}=13)$. Hence, there was a tendency for women with a mainly female cause of infertility to be heavier than the average weight for the whole group. About $7.7 \%$ of the women $(\mathrm{n}=90)$ were smokers while $1.6 \%$ $(\mathrm{n}=19)$ used snuff regularly (table 1$)$. In regard to previous pregnancies, $22.3 \%(n=263)$ had been pregnant previously. The corresponding numbers for women where the infertility was female or combined were $24.2 \%$ $(\mathrm{n}=129)$. The infertility was primary in $91.4 \%$ (1072) of the women, meaning that they had no previous children. Among the women diagnosed with female infertility $10 \%(n=45)$ had one or more child. Twelve per cent $(\mathrm{n}=141)$ of the women had experienced miscarriages previously. The corresponding numbers for women with a female or combined cause of infertility were $14.2 \%$ $(n=76)$, which was higher than for the other groups (table 1).

In regard to self-reported chronic illnesses, 356 $(29.5 \%)$ of the women reported one or more illness, which corresponded to $278(60.0 \%)$ of the women with a female cause of infertility, $65(20.1 \%)$ with a male cause of infertility, $29(20.1 \%)$ of those where the cause was combined and $84(24.7 \%)$ of those where the cause of infertility was unexplained. The remaining women either did not answer the question or stated that they had no chronic illnesses. The types of illnesses reported are displayed in table 2 . When gynaecological conditions were removed, the majority of which consisted of endometriosis, $21.3 \%$ of the women with a female cause of infertility stated that they had a chronic illness.

Thirty-three $(3.3 \%)$ of the women had been born before 37 gestational weeks while $0.4 \%(n=4)$ had been born before 32 weeks (table 3). The corresponding numbers for women diagnosed with mainly a female cause of infertility were $3.6 \% \quad(n=16)$ and $0.7 \% \quad(n=3)$, respectively. Thirty-seven women $(3.6 \%)$ weighed less than $2500 \mathrm{~g}$ at birth, of which 23 belonged to the female or combined infertility category. Only two (0.2\%) women had weighed less than $1500 \mathrm{~g}$ at birth; both of these belonged to either the female infertility category or the combined infertility category. Forty women (3.3\%) had been born SGA while 30 (2.5\%) women were born LGA (table 3).

The multinomial regression analyses showed no differences between the three categories (female/combined, male, unexplained) of women in regard to being born prematurely, LBW or LGA (table 4). However, those with a female or combined infertility were 2.5 times more likely to be born SGA than those with an unexplained cause of infertility ( $\mathrm{OR}=2.57$, CI 1.04 to 6.36, $\mathrm{p}=0.041)$. This difference remained when BMI and parity were controlled for $(\mathrm{OR}=2.73$, CI 1.02 to $7.34, \mathrm{p}=0.047)$. The bivariate regression analyses showed no difference as to being born preterm ( $<37$ weeks), SGA and LGA when women with female or combined causes of infertility were compared with those with a male or unexplained infertility factor. Women with a female or combined 
$\underline{\text { Table } 1 \text { Demographics and characteristics of previous pregnancies by infertility type }}$

\begin{tabular}{|c|c|c|c|c|c|c|c|c|c|c|c|c|}
\hline \multirow[b]{2}{*}{ Birth year* } & \multicolumn{2}{|c|}{ Female } & \multicolumn{2}{|l|}{ Male } & \multicolumn{2}{|c|}{ Combined } & \multicolumn{2}{|c|}{ Unknown } & \multicolumn{2}{|l|}{ Total } & \multicolumn{2}{|c|}{$\begin{array}{l}\text { Female } \\
\text { +Combined }\end{array}$} \\
\hline & $\bar{n}$ & Per cent & $\bar{n}$ & Per cent & $\bar{n}$ & Per cent & $\overline{\mathrm{n}}$ & Per cent & $\bar{n}$ & Per cent & $\bar{n}$ & Per cent \\
\hline \multicolumn{13}{|l|}{ BMI } \\
\hline$<20$ & 61 & 13.8 & 36 & 11.5 & 8 & 10.3 & 35 & 10.9 & 140 & 12.1 & 69 & 13.3 \\
\hline 20-24, 99 & 248 & 56.1 & 181 & 58.0 & 39 & 50.0 & 217 & 67.6 & 685 & 59.4 & 287 & 55.2 \\
\hline $25-29,99$ & 102 & 23.1 & 80 & 25.6 & 21 & 26.9 & 65 & 20.2 & 268 & 23.2 & 123 & 23.7 \\
\hline$>30$ & 31 & 7.0 & 15 & 4.8 & 10 & 12.8 & 4 & 1.2 & 60 & 5.2 & 41 & 7.9 \\
\hline \multicolumn{13}{|l|}{ Tobacco use } \\
\hline \multicolumn{13}{|l|}{ Smoking } \\
\hline Yes & 32 & 7.1 & 30 & 9.4 & 8 & 10.4 & 20 & 93.9 & 90 & 7.7 & 40 & 7.6 \\
\hline No & 420 & 92.9 & 290 & 90.6 & 69 & 89.6 & 307 & 6.1 & 1086 & 92.3 & 489 & 92.4 \\
\hline \multicolumn{13}{|l|}{ Snuff } \\
\hline Yes & 3 & 99.3 & 5 & 1.6 & 2 & 2.7 & 9 & 2.8 & 19 & 1.6 & 5 & 1.0 \\
\hline No & 447 & 0.7 & 313 & 98.4 & 73 & 97.3 & 319 & 97.2 & 1151 & 98.4 & 520 & 99.0 \\
\hline \multicolumn{13}{|c|}{ Number of previous pregnancies } \\
\hline 0 & 344 & 75.4 & 260 & 81.5 & 60 & 77.9 & 254 & 77.2 & 918 & 77.7 & 404 & 75.8 \\
\hline $1-2$ & 101 & 22.1 & 55 & 17.2 & 14 & 18.2 & 64 & 19.5 & 234 & 19.8 & 115 & 21.6 \\
\hline$\geq 3$ & 11 & 2.4 & 4 & 1.3 & 3 & 3.9 & 11 & 3.3 & 29 & 2.5 & 14 & 2.6 \\
\hline \multicolumn{13}{|c|}{ Number of previous miscarriages } \\
\hline 0 & 391 & 85.7 & 293 & 91.8 & 66 & 85.7 & 290 & 88.1 & 1040 & 88.1 & 457 & 85.7 \\
\hline $1-2$ & 58 & 12.7 & 26 & 8.2 & 11 & 14.3 & 32 & 9.7 & 127 & 10.8 & 69 & 12.9 \\
\hline$\geq 3$ & 7 & 1.5 & 0 & 0.0 & 0 & 0.0 & 7 & 2.1 & 14 & 1.2 & 7 & 1.3 \\
\hline \multicolumn{13}{|c|}{ Number of previous abortions } \\
\hline 0 & 429 & 94.3 & 297 & 93.1 & 73 & 96.1 & 299 & 90.9 & 1098 & 93.1 & 502 & 94.5 \\
\hline 1 & 23 & 5.1 & 20 & 6.3 & 3 & 3.9 & 25 & 7.6 & 71 & 6.0 & 26 & 4.9 \\
\hline$\geq 2$ & 3 & 0.7 & 2 & 0.6 & 0 & 0.0 & 5 & 1.5 & 10 & 0.8 & 3 & 0.6 \\
\hline \multicolumn{13}{|c|}{ Number of children } \\
\hline No children & 407 & 90.0 & 293 & 92.1 & 68 & 89.5 & 304 & 93.0 & 1072 & 91.4 & 475 & 90.0 \\
\hline$\geq 1$ child & 45 & 10.0 & 25 & 7.9 & 8 & 10.5 & 23 & 7.0 & 101 & 8.6 & 53 & 10.0 \\
\hline
\end{tabular}

${ }^{*}$ Displayed in median and range.

BMI, body mass index. 
Table 2 Prevalence of self-reported chronic illness by type of infertility

\begin{tabular}{|c|c|c|c|c|c|c|c|c|c|c|}
\hline & \multicolumn{2}{|c|}{ Female } & \multicolumn{2}{|c|}{ Male } & \multicolumn{2}{|c|}{ Combined } & \multicolumn{2}{|c|}{ Unexplained } & \multicolumn{2}{|l|}{ Total } \\
\hline & $\begin{array}{l}n \\
464 \\
\end{array}$ & $\begin{array}{l}\text { Per cent } \\
100\end{array}$ & $\begin{array}{l}\mathrm{n} \\
323 \\
\end{array}$ & $\begin{array}{l}\text { Per cent } \\
100\end{array}$ & $\begin{array}{l}\mathbf{n} \\
79\end{array}$ & $\begin{array}{l}\text { Per cent } \\
100\end{array}$ & $\begin{array}{l}\mathrm{n} \\
\mathbf{3 4 0} \\
\end{array}$ & $\begin{array}{l}\text { Per cent } \\
100\end{array}$ & $\begin{array}{l}\mathbf{n} \\
1206 \\
\end{array}$ & $\begin{array}{l}\text { Per cent } \\
100\end{array}$ \\
\hline \multicolumn{11}{|l|}{ Chronic illness } \\
\hline Dermatological & 4 & 0.9 & 0 & 0.0 & 1 & 1.3 & 2 & 5.9 & 7 & 0.6 \\
\hline $\begin{array}{l}\text { Congenital malformations or } \\
\text { chromosomal abnormalities }\end{array}$ & 5 & 1.1 & 1 & 0.3 & 1 & 1.3 & & 5.9 & 9 & 0.7 \\
\hline Pulmonary & 22 & 4.7 & 12 & 3.7 & 3 & 3.8 & 15 & 4.4 & 52 & 4.3 \\
\hline Asthma & 20 & & 12 & & 2 & & 15 & & 49 & \\
\hline Other & 2 & & 0 & & 1 & & 0 & & 3 & \\
\hline Gastrointestinal & 13 & 2.8 & 3 & 0.9 & 2 & 2.6 & 14 & 4.1 & 32 & 2.7 \\
\hline Inflammatory bowel disease & 6 & & 1 & & 1 & & 7 & & 15 & \\
\hline Irritable bowel syndrome & 1 & & 0 & & 1 & & 5 & & 7 & \\
\hline Coeliac disease & 4 & & 0 & & 0 & & 1 & & 5 & \\
\hline Other & 2 & & 2 & & 0 & & 1 & & 5 & \\
\hline Psychiatric & 13 & 2.8 & 9 & 2.8 & 2 & 2.6 & 6 & 1.8 & 31 & 2.6 \\
\hline Depression & 11 & 6 & 1 & 3 & 21 & & & & & \\
\hline Other & 3 & 3 & 1 & 3 & 10 & & & & & \\
\hline Endocrinological & 22 & 4.7 & 14 & 4.3 & 10 & 7.9 & 18 & 5.3 & 64 & 5.3 \\
\hline Hypothyroidism & 12 & & 6 & & 4 & & 12 & & 34 & \\
\hline Other thyroid disease & 2 & & 0 & & 1 & & 2 & & 5 & \\
\hline Diabetes & 2 & & 6 & & 2 & & 3 & & 13 & \\
\hline Obesitas & 2 & & 1 & & 1 & & 0 & & 4 & \\
\hline Hypertension & 2 & & 1 & & 1 & & 0 & & 4 & \\
\hline Hyperprolactinaemia & 2 & & 0 & & 1 & & 1 & & 4 & \\
\hline Gynaecological & 79 & 17.0 & 2 & 0.6 & 8 & 10.1 & 3 & 0.9 & 92 & 7.6 \\
\hline Endometriosis & 76 & & $2^{*}$ & & 8 & & $3^{*}$ & & 89 & \\
\hline Other & 3 & & 0 & & 0 & & 0 & & 3 & \\
\hline Neurological & 8 & 1.7 & 6 & 1.9 & 1 & 1.3 & 6 & 1.8 & 21 & 1.7 \\
\hline Multiple sclerosis & 2 & & 1 & & 0 & & 1 & & 4 & \\
\hline Epilepsy & 4 & & 2 & & 0 & & 0 & & 6 & \\
\hline Migraine & 2 & & 2 & & 1 & & 5 & & 10 & \\
\hline Other & 0 & & 1 & & 0 & & 0 & & 1 & \\
\hline Rheumatological disease & 2 & 0.4 & 1 & 0.3 & 1 & 1.3 & 7 & 2.1 & 11 & 0.9 \\
\hline Fibromyalgia & 1 & 0.2 & 2 & 0.6 & 0 & 0.0 & 1 & 0.3 & 4 & 0.3 \\
\hline Muscle and joint dysfunctions & 5 & 1.1 & 4 & 1.2 & 1 & 1.3 & 2 & 0.6 & 12 & 1.0 \\
\hline $\begin{array}{l}\text { Other symptom, disorder or previous } \\
\text { operations }\end{array}$ & 6 & 1.3 & 7 & 2.2 & 2 & 2.6 & 10 & 3.4 & 25 & 2.1 \\
\hline
\end{tabular}

cause of infertility were about twice as likely to be born with LBW (<2500 g) compared with those with a male or unexplained infertility $(\mathrm{OR}=2.26$, CI 1.13 to 4.52 , $\mathrm{p}=0.021)$. The differences remained when $\mathrm{BMI}$ and parity were controlled for $(\mathrm{OR}=2.40$, CI 1.13 to 5.07 , $\mathrm{p}=0.022$; table 4).

\section{DISCUSSION}

The present study aimed to investigate the distribution of preterm birth, LBW, SGA and LGA in a population of Swedish women seeking infertility treatment and to compare those where the cause of infertility was female with those where the infertility was male and/or unexplained. The results of the study showed no differences in the distribution of preterm birth or LGA between the categories of women. However, women seeking infertility treatment due to a female factor were about twice as likely to have been born with LBW compared with those where the cause of infertility was male or unexplained, while those with a female factor were about twice as likely to be born SGA compared with those where the infertility factor was unexplained. The bivariate logistic regression analysis showed that the risk of being born with LBW was twice as high among women with a female infertility factor compared with those where the cause of the infertility was male or unexplained. This difference remained when parity and BMI were controlled for. Thus, this study found an association between being born with LBW and subsequent infertility in women, results which are in accordance with our hypothesis. Also, the multinomial regression analyses showed that the risk of being born SGA was increased 2.5 times in women where the cause 
Table 3 Birth characteristics by infertility type

\begin{tabular}{|c|c|c|c|c|c|c|c|c|c|c|c|c|}
\hline \multirow[b]{2}{*}{ Infertility type } & \multicolumn{2}{|c|}{ Female } & \multicolumn{2}{|c|}{ Male } & \multicolumn{2}{|c|}{ Combined } & \multicolumn{2}{|c|}{ Unexplained } & \multicolumn{2}{|l|}{ Total } & \multicolumn{2}{|c|}{$\begin{array}{l}\text { Female } \\
\text { +Combined }\end{array}$} \\
\hline & $\begin{array}{l}n \\
464\end{array}$ & $\begin{array}{l}\text { Per cent } \\
38.5\end{array}$ & $\begin{array}{l}\mathrm{n} \\
323\end{array}$ & $\begin{array}{l}\text { Per cent } \\
26.7\end{array}$ & $\begin{array}{l}n \\
79\end{array}$ & $\begin{array}{l}\text { Per cent } \\
6.6\end{array}$ & $\begin{array}{l}\mathrm{n} \\
340\end{array}$ & $\begin{array}{l}\text { Per cent } \\
28.2\end{array}$ & $\begin{array}{l}n \\
1206\end{array}$ & $\begin{array}{l}\text { Per cent } \\
100\end{array}$ & $\begin{array}{l}n \\
543\end{array}$ & $\begin{array}{l}\text { Per cent } \\
45.1\end{array}$ \\
\hline \multicolumn{13}{|c|}{ Preterm birth (weeks) } \\
\hline Yes & 13 & 3.4 & 6 & 2.3 & 3 & 4.6 & 10 & 3.4 & 33 & 3.3 & 16 & 3.6 \\
\hline No & 368 & 96.6 & 256 & 97.7 & 62 & 95.4 & 283 & 96.6 & 980 & 96.7 & 430 & 96.4 \\
\hline \multicolumn{13}{|l|}{ Very $(<32)$} \\
\hline Yes & 3 & 0.8 & 0 & 0.0 & 0 & 0.0 & 1 & 0.3 & 4 & 0.4 & 3 & 0.7 \\
\hline No & 378 & 99.2 & 262 & 100 & 65 & 100 & 292 & 99.7 & 1009 & 99.6 & 443 & 99.3 \\
\hline \multicolumn{13}{|l|}{ Birth weight } \\
\hline \multicolumn{13}{|c|}{ LBW (<2500 g) } \\
\hline Yes & 17 & 4.5 & 6 & 2.3 & 6 & 9.2 & 7 & 2.4 & 37 & 3.6 & 23 & 5.1 \\
\hline No & 365 & 95.5 & 256 & 97.7 & 59 & 90.8 & 286 & 97.6 & 978 & 96.4 & 424 & 94.9 \\
\hline \multicolumn{13}{|c|}{ VLBW (<1500 g) } \\
\hline Yes & 1 & 0.3 & 0 & 0.0 & 1 & 1.5 & 0 & 0.0 & 2 & 0.2 & 2 & 0.4 \\
\hline No & 381 & 99.7 & 262 & 100 & 64 & 98.5 & 293 & 100 & 1013 & 99.8 & 445 & 99.6 \\
\hline \multicolumn{13}{|c|}{$\begin{array}{l}\text { Size in relation to mean weight for gestational age } \\
\text { SGA }(<-2 S D)\end{array}$} \\
\hline Yes & 17 & 3.7 & 10 & 3.1 & 7 & 8.9 & 6 & 1.8 & 40 & 3.3 & 24 & 4.4 \\
\hline No & 447 & 96.3 & 312 & 96.9 & 72 & 91.1 & 334 & 98.2 & 1181 & 96.7 & 519 & 95.6 \\
\hline \multicolumn{13}{|l|}{ LGA (>2SD) } \\
\hline Yes & 12 & 2.6 & 9 & 2.8 & 0 & 0.0 & 9 & 2.6 & 30 & 2.5 & 12 & 2.2 \\
\hline No & 452 & 97.4 & 313 & 97.2 & 79 & 100 & 331 & 97.4 & 1191 & 97.5 & 531 & 97.8 \\
\hline
\end{tabular}

of infertility was female compared with those where the cause was unexplained. Interestingly, this study also showed that women with a female or combined infertility were more likely to be obese compared with women of the other infertility categories. The obesity could of course be the cause of infertility in these women. However, in accepting these women, exceptions from the clinic guidelines were made. Thus, it is more likely that the cause of infertility was well defined in these women and that the obesity therefore was not considered important. As many as $22.3 \% \quad(n=263)$ of all women had been pregnant previously and $8.6 \%$ $(n=101)$ had children. A higher percentage of those with a female cause of infertility had previously experienced a miscarriage compared with women in the other groups.

It appears that there is an association between being born with LBW and being diagnosed with infertility later on in life. While there are no previous studies on this topic, Ekholm et at found that women born with VLBW were less likely to give birth during their early reproductive years. We were not able to include VLBW in our analyses due to the too small numbers, but if there is an over-representation of women born with LBW among those diagnosed with infertility, it seems likely that weighing even less at birth should also increase the risk of female infertility. Perhaps the results of Ekholm et a ${ }^{9}$ were an early manifestation of an increased risk of infertility in these women.
So what could be the reason for these associations? Could it be that growth restriction influences the function of the reproductive organs resulting in reproductive impairment later on in life? Growth restriction has been linked to smaller internal genitalia and reduced ovulation rate in women, ${ }^{14}{ }^{15}$ results which could be associated with those of the present study.

This study has several limitations. First of all, the sample size was relatively small, which negatively influences the validity of the results. Also, the women diagnosed with infertility were compared with those who were not infertile themselves but who had a spouse with a male infertility factor or the women where the cause of infertility within the couple was unexplained. The category with an unexplained cause of infertility causes difficulties in interpreting the results since it may contain individuals where the cause of infertility was yet to be discovered. It is also possible that the causes of the couples' inability to have children are due to other reasons than infertility such as sexual dysfunction and that not all couples are truthful in reporting the length of time that they have tried to conceive and thus are fertile or subfertile rather than infertile. A strength of this study is the that it is based on robust data from the MBR, decreasing dependence on unsecure patient data on, for example, birth weights, which could include recall bias. However, all registers may also contain errors, but these limitations should affect all groups equally. Another strength is that the infertility diagnoses were 
Table 4 Birth characteristics by infertility type: OR

Multinomial regression,

\section{controls}

\section{p Value OR}

Variables by infertility type

Preterm (<37 weeks)

Female/combined (ref) 0.291

Male

Female/combined (ref) $\quad 0.597$

Unexplained

Female/combined (ref) -

Male/unexplained

LBW (<2500 g)

Female/combined (ref) $\quad 0.095$

Male

Female/combined (ref) $\quad 0.057$

Unexplained

Female/combined (ref) -

Male/Unexplained

LGA

Female/combined (ref) 0.595

Male

Female/combined (ref) $\quad 0.712$

Unexplained

Female/combined (ref) -

Male/unexplained

SGA

Female/combined (ref) $\quad 0.341$

Male

Female/combined (ref) $\quad 0.047^{*}$

Unexplained

Female/combined (ref) -

Male/unexplained

*Significant at the $p=0.05$ level.

LBW, low birth weight; LGA, large for gestational age; SGA, small for gestational age.
Multinomial regression,

no controls

p Value OR Cl
Binary logistic regression,

controls

p Value OR Cl
Binary logistic regression,

no controls

P Value OR Cl 
determined by the physicians conducting the infertility investigations, thus being independent from the contributors to the study. Since only Swedish women were included, the results of this study cannot be generalised to include all women as the causes of infertility differ in developing countries from the western world. In future studies, we will describe the type of treatment and treatment outcome in the present study population and also the birth characteristics of their male partners.

In conclusion, this study indicates that there is an association between being born with LBW and/or SGA and infertility in women. As medical research and care advances, more infants will be born and survive with LBW and/or SGA, which in turn might influence future need of infertility treatment. The present study is the first on this topic; thus, more studies are needed to verify these possible associations and to determine their nature.

Contributors JV participated in data collection, designed the plan for data analyses, analysed the data as well as drafted and revised the paper. She is a guarantor. $\mathrm{MH}$ and $\mathrm{AJ}$ designed the trial and revised the paper. MB participated in data collection, designed the plan for data analyses, cleaned and analysed the data and revised the paper. GS had the original idea for the study, designed data collection tools and the trial, analysed the data and revised the paper. She is a guarantor.

Funding This study was supported by grants from the Health Research Council of the Southeast of Sweden and ALF, County Council of Östergötland grant number F 82631.

\section{Competing interests None.}

Ethics approval The study has been approved by the Human Research Ethics Committee, in Linköping 03-556, 07-M66 08-08-M 233-8.

Provenance and peer review Not commissioned; externally peer reviewed.

Data sharing statement Full dataset and statistical code available from the corresponding author at josefin.vikstrom@lio.se. Consent was not obtained, but the presented data are anonymised and risk of identification is low. All authors, external and internal, had full access to all of the data (including statistical reports and tables) in the study and can take responsibility for the integrity of the data and the accuracy of the data analysis.

Open Access This is an Open Access article distributed in accordance with the Creative Commons Attribution Non Commercial (CC BY-NC 3.0) license, which permits others to distribute, remix, adapt, build upon this work noncommercially, and license their derivative works on different terms, provided the original work is properly cited and the use is non-commercial. See: http:// creativecommons.org/licenses/by-nc/3.0/

\section{REFERENCES}

1. Barker DJP. Mothers, babies and health in later Life. 2nd edn. Edinburgh, Scotland: Churchill Livingstone, 1998.

2. Hodgson ED. Perinatal programming: early life determinants of adult health and disease. Abingdon, Oxon: Tailor \& Francis, 2006.

3. McMillen IC, Robinson JS. Developmental origins of the metabolic syndrome: prediction, plasticity, and programming. Physiol Rev 2005;85:571-633.

4. Tu YK, West R, Ellison GT, et al. Why evidence for the fetal origins of adult disease might be a statistical artifact: the "reversal paradox" for the relation between birth weight and blood pressure in later life. Am J Epidemiol 2005;161:27-32.

5. Lobel M, Cannella DL, Graham JE, et al. Pregnancy-specific stress, prenatal health behaviors, and birth outcomes. Health Psychol 2008;27:604-15.

6. Marsál K, Persson PH, Larsen T, et al. Intrauterine growth curves based on ultrasonically estimated foetal weights. Acta Paediatr 1996;85:843-8.

7. National Board of Health and Welfare, Centre for epidemiology. The Swedish Medical Birth Register; A Summary of Content and Quality. 2003. http://www.socialstyrelsen.se/Lists/Artikelkatalog/Attachments/ 10655/2003-112-3_20031123.pdf (accessed 4 Feb 2013).

8. National Board of Health and Welfare, Centre for Epidemiology. Pregnancies, Deliveries and Newborn Infants; The Swedish Medical Birth Register 1973-2007; Assisted Reproduction, treatment 19912006. 2009. http://www.socialstyrelsen.se/Lists/Artikelkatalog/ Attachments/8316/2009-125-5_20091255_rev3.pdf (accessed 4 Feb 2013).

9. Ekholm K, Carstensen J, Finnström O, et al. The probability of giving birth among women who were born preterm or with impaired fetal growth: a Swedish population-based registry study. Am J Epidemiol 2005;15:161.

10. Selling KE, Carstensen J, Finnström O, et al. Hospitalization in adolescence affects the likelihood of giving birth: a Swedish population-based register study. Acta Paediatr 2009;98:561-6.

11. Phillips DI, Handelsman DJ, Eriksson JG, et al. Prenatal growth and subsequent marital status: longitudinal study. BMJ 2001; 322:771.

12. Selling KE, Carstensen J, Finnström O, et al. Hospitalizations in adolescence and early adulthood among Swedish men and women born preterm or small for gestational age. Epidemiology 2008;19:63-70.

13. Selling KE, Finnstrom O, Carstensen J, et al. Intergenerational effects of preterm birth and impaired fetal growth: a population based study of Swedish mother-offspring pairs. BJOG 2006;113:430-40.

14. Ibanez L, de Zegher F. Puberty after prenatal growth restraint. Horm Res 2006;65:112-15.

15. Cicognani A, Alessandroni R, Pasini A, et al. Low birth weight for gestational age and subsequent male gonadal function. $J$ Pediatr 2002;141:376-9.

16. World Health Organization. Obesity: preventing and managing the global epidemic. Geneva, Switzerland: World Health Organization, 2000. WHO technical report series 894.

17. Harlow BL, Vitonis AF, Sparen P, et al. Incidence of hospitalization for postpartum psychotic and bipolar episodes in women with and without prior prepregnancy or prenatal psychiatric hospitalizations. Arch Gen Psychiatry 2007;64:42-8.

18. Keller M, Felderhoff-Mueser U, Lagercrantz $\mathrm{H}$, et al. Policy benchmarking report on neonatal health and social policies in 13 European countries. Acta Paediatr 2010;99:1624-9. 